\title{
Textual Database on Women and Social Movements, International, 1800-2010
}

Review of: Women and Social Movements, International

Author/Compiler: Thomas Dublin and Kathryn Kish Sklar

Repository: http://wasi.alexanderstreet.com/

Date of Posting: September 2013, with subsequent updates

Size: 150,000 pages of documents

Licensing: Materials protected by copyright ${ }^{1}$

Volume 2-3, No. 2 (2014-2015) | ISSN 2169-0812 (online)

DOI 10.5195/jwhi.2015.34 | http://jwhi.pitt.edu 
Years of teaching about women and social movements at Binghamton University led Thomas Dublin and Kathryn Kish Sklar to create and then expand a campus-oriented website that ultimately resulted in two large-scale textual resources, Women and Social Movements in the US (WASM) and Women and Social Movements, International (WASMI). ${ }^{2}$ This review focuses on WASMI because it is more recent and because it addresses the difficulties inherent in a world-wide dataset. The dataset has received considerable recognition-in particular, the editors were invited to present at a plenary session at the worldwide congress of historians (August 2015) in Jinan, China, at which they gave a thorough presentation.

Inclusion of this review in the Journal of World-Historical Information is also a step in a new direction for this journal, in that it extends previous reviews of tabular or structured datasets to incorporate textual datasets. One dimension of this review focuses on comparison of textual and tabular datasets. The WASMI search function can trace words anyplace throughout the whole archive, listing the various references. That is very different from tabular datasets, where it is generally necessary to specify documents first in order to look within them, or where one may search on metadata describing multiple documents but where one cannot search directly on the data. In addition to this basic strength of this textual site, WASMI is of interest because of the work of its creators in data collection and preparation, the technology of the site, the collaborative organization and the funding of the site.

The WASMI database includes 4660 sources extending to 150,000 pages and 124 online audio and video resources, plus 25 scholarly essays. This online resource is large, wide ranging, and well organized. The resources have been coded in detail. The purpose and subject matter of WASMI is documentation on women's activity and leadership in social movements, as seen through main feminist figures and main institutions, organizations, and conferences. Examples range from women's rights conferences in the nineteenth century to substantial documentation on the United Nations Decade of Women, 1975-1985. Numerous guides present the documents. An overall browsing section lists works as: All works, Archives, Scholarly Essays, People, Places, Organizations, Themes, All Subjects, and Proceedings. Simple and advanced searches enable users to enter criteria for selecting documents by keywords - coded by the editors but also open to selection by users. A "Help" section presents a bulleted list of topics for further inquiry, including Getting Started, Browsing, Searching, Playlists, Video Player, Image Viewer, and Secondary Essays.

For users of this resource, it is a straightforward, attractive, and easily navigable site. The authors and their staff have added a great deal of descriptive and interpretive information to the documents, so that one can read the evidence at multiple levels. For instance, individual documents have been coded by the authors to list all individual persons, giving their nationality and institutional affiliation where available. The simple search, available on the home page, gives rapid responses to queries on key terms selected by users or suggested in the site's descriptive material. Through it I found that 999 documents referred to "industry" and 779 to "agriculture." Similarly, 702 documents used the term "urban," 1079 used "rural," and 1220 documents included the term "vote." These simple searches give an idea of the overall dimensions of the dataset. Beyond a certain limit, the search does not attempt to keep track of details: the search reported that there were "thousands" of instances for the terms family, city, country, children, women, and woman. The advanced search enables narrowing searches within more than 20 categories. For categories such as author, archives, etc., the user can select specific terms by menu. Users may also limit authors by gender, by nation, or by organizations to which they belonged. The term "human rights" gave 958 total responses, and I was able to begin breaking them down by year to see when the term's use expanded. Similarly, I could see that use of the term "feminism" could be traced by year or by place. 
The "playlists" are groups of documents assembled by users for teaching purposes; the playlists remain online for the use of others. Users can annotate, edit, copy and share playlists. In fact, most of the 28 playlists were prepared at Binghamton and at Alexander Street Press. One is a Swiss Playlist, with ten document of from three to over 50 pages in English, French, and German, addressing Swiss women in international organizations from 1928 to1995. Another, prepared by Nathalie Duval, includes nine documents on women's organizations in southern and eastern Africa from 1958 to 1995.

For builders of online datasets with a global orientation, WASMI provides some valuable lessons. By searching on "Dublin" or by browsing the list of scholarly essays, one can reach an essay by Dublin, entitled "Constructing the WASMI Database," that is parallel to the Dublin-Sklar essay on WASM. This review of the process of constructing the dataset is of general value for any developer of an online dataset. Indeed, it suggests that such a "how we got there" essay should be included in any complex online dataset. The essay and the site in general confirm the importance of collaborative organization of creating it and sustaining it. Numerous Binghamton students played roles in researching and documenting the selected documents. Plans and progress of the site were discussed at large meetings of historians, notably at the Berkshire Conference on History. The list of Advisory Board members exceeds a hundred, so it appears that members contribute more as individuals than as a group. Extensive documentation of the site, including biographical information of many of the authors of documents, reflect such collaboration.

For manuscripts and rare published materials, the authors relied especially on the Sophia Smith Collection at Smith College, the Schlesinger Library at Harvard, the Peace Collection at Swarthmore College and the Library of Congress, but also on many other repositories. In addition, audio and video tapes were recorded in 2011 at the Berkshire Conference on the History of Women. In its technology, WASMI relies on Zotero, a bibliographical program created by the Center For History and New Media (George Mason University). English-language documents were scanned through OCR but documents in other languages were entered manually. The business model of the site is that of individual and institutional subscriptions through Alexander Street Press. Much of the site's information is available without registration, but any serious searching requires that the user be registered.

The site's global dimension relies especially on the links of American women activists to others around the world. A more systematically global resource could be imagined, yet WASMI demonstrates the remarkable degree of cross-national connection among women activists from the mid-nineteenth century on. Of the documents in WASMI, 7\% are in languages other than English, mostly in Spanish and French: abstracts are provided for documents not in English.

In one sense, users are left to interpret the documents on their own, except as guided by the descriptions of documents. In another sense, a rather full set of interpretive materials has been provided in the 25 commissioned scholarly essays. Included are essays by Harriet Alonso on the Women's International League for Peace and Freedom, Iris Berger on African women and decolonization, Eileen Boris on the International Labor Organization and women, and Nancy Cott on the holdings of the Schlesinger Library-and Dublin's essay on constructing the site.

The sum of the materials prompts one further comment from this reviewer. The resource is indeed, as labeled, documentation of Women and Social Movements, International. Nevertheless, given the nature of the documents, the resource adds up to an approach to women and social movements that is not exactly "bottom-up." In conveying the voices of leaders of women's movements and female voices from the tribune in international conferences, this resource seems best at conveying an intermediate range of voices in social movements. There is little here that is 
"top-down," representing the social and economic interests that kept women within limited legal rights and without formal participation in politics. (Some of these top-down interests are described and criticized in the documents of this resource.) That is, one hears irregularly the voices of women more generally-those who chose whether or not to give support to those documented here. This wider range of women did much to determine the success or failure of any initiative through their individual decisions to speak out or to step back and focus on their individual struggles. It may be that the materials of WASMI, analyzed with sufficient acuity, can give new insights into the interplay between the women documented here in greatest detail and two groups of others: the larger numbers of women whose vision they sought to articulate and the power brokers with whom they sought to bargain new and more equitable social compromises.

The significance of this site is in confirming the feasibility and the sustainability of a large corpus of primary and secondary documents, thoroughly documented, and fully searchable. This work has been completed with a relatively basic level of technology, so it shows the benefits of care and persistence. This resource is of great value for scholars and students seeking information on social history, gender relations and many related subjects for the past 150 years. In addition, it is of great interest for those who work to build online resources in tabular or structured data, as it reminds one of the benefits of being able to search across the full database and shows the range of tasks that can be completed with textual data. Perhaps this site will suggest some handy hints to other users. To conclude by mentioning one among many striking documents in the collection: there is an report of the 1919 International Congress of Women in Zurich, recorded by the Women's International League for Peace and Freedom, and listed as 525 pages in length.

\section{NOTES}

${ }^{1}$ The majority of material in the database is protected by copyright. Reprinting or reproducing content from this database for uses other than teaching or personal research will require separate permission from the copyright holders of the material in question.

2 The earlier online database is Women and Social Movements in the United States. The authors describe this site and its development in Kathryn Kish Sklar and Thomas Dublin, "Keeping up with the Web, 1997-2008: Women and Social Movements in the United States” Perspectives on History (May 2009).

\section{(cc) EY 1 Articles in this journal are licensed under a Creative Commons Attribution 4.0 United States}

License.

\section{ULIS D-Sorle}

This journal is published by the University Library System of the University of Pittsburgh as part of its D-Scribe Digital Publishing Program and is cosponsored by the University of Pittsburgh Press. 